\title{
Bioethics in developing countries: ethics of scarcity and sacrifice
}

\author{
Charles Olweny University of Manitoba, Canada
}

\section{Author's abstract}

Contemporary issues such as euthanasia, surrogate motherhood, organ transplantation and gene therapy, which occupy the minds of ethicists in the industrialized countries are, for the moment, irrelevant in most developing countries. There, the ethics of scarcity, sacrifice, cross-cultural research, as well as the activities of multinational companies, are germane. In this article, only the ethics of scarcity and sacrifice will be discussed.

Structural adjustment programmes, designed to solve the economic problems of the developing countries, muddied the waters. The dilemma confronting practitioners in developing countries is how to adhere to the basic principles of medical ethics in an atmosphere of hunger, poverty, war and ever-shrinking and often non-existent resources. Nowhere else in the world is the true meaning of scarcity portrayed as vividly as in the developing countries. Consequently, the doctor's clinical freedom may have to be sacrificed by the introduction of an essential drugs list and practice guidelines.

The principle of greater good, while appealing, must be carefully interpreted and applied in the developing countries. Thus, while health promotion and disease prevention must be the primary focus, health planners should avoid pushing prevention at the expense of those currently sick.

Health care reform in developing countries must not merely re-echo what is being done in the industrialized countries, but must respond to societal needs and be relevant to the community in question.

\section{Definition}

Ethics is the science of morals. While ethics is practised at a personal level, it impacts on the rest of society, the attributes and cultural values of which often differ from the individual's. Unfortunately, personal values do not coincide with professional codes of conduct or societal values. Legal justice, for instance, does not necessarily equate to social or societal justice, as the Rodney King ruling revealed. Rodney King was filmed being beaten by the Los

\section{Key words}

Bioethics; developing countries; scarcity and sacrifice.
Angeles police. In a court hearing the policemen were acquitted by the jury. The policemen were thus legally and technically innocent. The Los Angeles community thought otherwise as evidenced by the Newsweek Poll of 30th April-1st May, 1992 (1). The Simi Valley verdict sparked off an uprising that was more destructive than any hurricane in the history of the United States (2). The community saw the Simi Valley verdict as a miscarriage of justice and 'spoke' out loudly and clearly.

Bioethics is the interdisciplinary study of problems created by medical values and progress. The values which defined society a few years ago are changing. Ethics is therefore not static; it is a dynamic process. In the last forty years major changes have occurred in the health care system. There has been an explosion of medical knowledge leading to a better understanding of disease process and pathophysiology. There have also been tremendous technological advances, especially in the diagnostic field, with the introduction of computerized tomography scanning and magnetic resonance imaging. At the same time, societal attitudes and morals have changed. The lay public has become increasingly health conscious. Pre-eminence is now placed on an individual patient's role in decision-making. Patients are encouraged now, more than ever before, to take charge of their destiny to the very end.

\section{Paradigm shift}

In the public's eye, medicine has been transformed from a revered profession into a high-technology and rather impersonal business. The doctor is now regarded as a highly trained technologist and viewed as a purveyor of cold scientific facts. The doctor, who was once considered as humane and caring, is now seen as preoccupied and aloof. The phenomenon of value change is complex. This paradigm shift, as it is sometimes called, together with technological advances, have led to value re-standardization. Abnormalities that once were accepted as not treatable are now seen as conditions that require prevention, treatment or both. Advances in genetic engineering, organ transplantation, surrogate 
motherhood and gene therapy induce developments which demand an even understanding of their values and utility. Unfortunately the ethical issues surrounding the application of these technological advances are now being settled by tribunals, rather than by health care professionals after appropriate consultations with the families concerned.

There is yet another dimension to the shift. Consideration of these issues has moved from medical journals and specialty conferences to public media, political rallies, town hall meetings and living-room discussions. The right to essential health care for all is now recognized explicitly or implicitly by virtually everyone as being equally as meritorious as the rights to justice, basic education and public security.

The shift has now given birth to a new form of medical ethics which to me appears neither rational nor philosophical. The new medical ethics is politically driven and fuelled by economic concern. There is an ever-growing shift from reliance solely on medical experts to economic experts who now appear to be giving directives. Young physicians are being taught that saving resources and practising cost-effective medicine is their overriding priority. Physicians previously regarded as patient advocates have now joined the ranks of policy planners and politicians as guardians of resources and the patient appears to be the loser.

There is the shift of power in the health care system from the physician on the one hand to the politician, policy planner and lawyer on the other. The political first-order decisions are made about which area of society will bear the brunt of sacrifice, with money being moved from the less politically powerful group to the more powerful ones (political lobby). In the words of Colleen Clement, lawyers and insurers are crowding out physicians (3). Patients now need a strong economic base to hire lawyers and advocates to advance their cause.

\section{Medical values}

Important values in medicine are said to include access, efficiency, equality, humane delivery, stateof-the-art technology and patient and professional autonomy (4). Unfortunately, all of these cannot be maximized in a single system. In the developing countries, most of these values are difficult to come by. Health care access, for instance, is one major issue that health care providers in developing countries have failed adequately to address. The population in these countries is to be found predominantly in the rural areas, and yet the health care facilities are located primarily in the urban centres. The problem of access is not peculiar to developing countries. In Canada, it is estimated that 26 per cent of health care spending is dedicated to only six per cent of the population, most of whom are likely to die within six months (5). The geographic size of Canada results in poor distribution of health $\overline{\bar{\sigma}}$. care equitability throughout the country. High-? technology diagnostic and therapeutic equipment is $\vec{F}$ located mainly in tertiary centres and specialists ${ }_{-}^{+}$ aggregate in cities. The health care reform process is등 attempting to rectify this anomaly by trimming down $\overline{\bar{n}}$. services at the tertiary institutions and, hopefully, $\overrightarrow{\mathbb{D}}$ transferring them in due course to rural areas. In 1945, President Harry Truman proposed a universal ${ }^{\infty}$ health plan for all Americans. Today, nearly fifty $\vec{\circ}$ years later, the American people are still waiting. $\vec{A}$ About 35-40 million Americans are uninsured and therefore have no access to their apparently sophisticated system. It is no wonder health care ${ }^{\mathbb{D}}$ reform was one of the main issues during the $1992 \mathrm{O}$ American presidential elections. Once elected, $\omega$ President Clinton moved swiftly to fulfil his $\vec{\sigma}$ campaign promise (6) by addressing the issue of health care reform. The prospect for fundamental change now seems within reach. The approach taken $\vec{C}$ endeavours to find a lasting solution that will controld costs and improve both access and quality (7).

At the Alma Ata Conference in 1978, the World Health Organization, together with 66 other United吕 Nations bodies, declared health for all by the year $\overrightarrow{0}$ 2000 (8). As that date approaches, that dream is $\operatorname{Rr} 8$ from reality, and it now looks as though declaration should have read 'health for all in 2000 years!'.

No health care system has met the conflictingo objectives of providing ready access to high quality $\frac{\mathrm{O}}{\mathrm{Q}}$ care at a low cost to everyone who needs it while at $\varrho$ the same time granting the patients and health care $\overrightarrow{\overrightarrow{0}}$ professionals the freedom of choice.

\section{Increasing cost does not mean better health}

The most expensive facilities are not necessarily the best. Developed countries have been spending an increasing percentage of their gross national product? (GNP) on health. These industrialized countries have not proven conclusively, either to themselves or? to the rest of the world, that such increased expenditure leads to improved health (9). Applying such measures of success as life expectancy and N infant mortality, it can be demonstrated that increased spending does not equate with improved health (Table 1). Thus Japan, which devotes an ${ }^{\omega}$ amount less than 50 per cent of the health care expenditure of the United States, has a higher life्己 expectancy and a far lower infant mortality rate More recent 1990 figures indicate the United States spent nearly $\$ 670$ billion on health care $(\$ 2,566$ per capita) while Canada sent $\$ 1,770$ and the Unitedo Kingdom only $\$ 972$ per capita respectively (10). It is estimated that the 1993 United States expenditure on health will top $\$ 900$ billion, that is $\$ 3,380$ pere citizen. This exponential rise in United States health 
Table 1

Health expenditure (per capita, US \$) Life expectancy (years)

Infant mortality (per 1000 live births)

United States
2051
$75 \cdot 0$
$10 \cdot 1$

Source: $1987 / 88$ OECD and WHO data

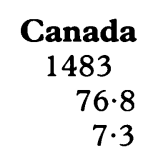
Sweden
1233
$77 \cdot 2$
$6 \cdot 1$

care cost is due to a number of factors. First, the United States treats health care as a market commodity and not as a social good, and its distribution is partly related to market forces viz ability to pay rather than medical need (11). Second, defensive medicine forces care providers continually to add to the tests needed before diagnosis, and some of these have marginal benefits. It has been suggested that even if we were to devote 100 per cent of the GNP to health care, it still would not be enough. This is because the human desire to be free of pain and disease and to live a longer and healthier life is insatiable (12).

\section{Resource allocation}

Resources belong to society and therefore society expects a certain order in their allocation and utilization. Resource allocation is the primary responsibility of any health care facility. Human communities exist to promote and share the common good, including access to essential health care among their members. The high financial cost of medical technology which benefits only a select few, limits resources for diagnosis, treatment, health promotion and disease prevention which could benefit many people. This violates the principle of distributive justice, a societal obligation to distribute its goods equitably to all its members. The need to contain health care costs has become an issue of global concern and laws are being enacted to ensure that costs are affordable $(13,14,15)$. In recent years the delivery of health care has come under intense and unprecedented scrutiny $(16,17)$. Health programme evaluation has become a key component of health services research; mainly because the health profession has attracted practitioners with expertise in the scientific analysis of interventions and the availability of large data bases have made such analysis possible.

\section{Developing countries}

Developing countries cover two-thirds of the earth's surface and are home to 3.5 billion inhabitants, constituting three-quarters of all humanity. The phrase 'developing countries' appears to be synonymous with poverty, powerlessness, misrule, inequality and waste. It probably does not matter which term is applied, whether these countries are called Third World countries for political reasons or charitably referred to as developing countries or strategically as the South. It all adds up to the same thing: want. The people in developing countries have an average income of only six per cent of that of the people in the developed industrialized North.

The 1980s was a decade of pervasive economic crisis. There is evidence that both health status and government expenditure on health in the developing countries suffered. During that decade, the proportion of government spending devoted to health fell in most of sub-Saharan Africa, in 50 per cent of Latin American, and in 30 per cent of Asian countries. In the thirty-seven of the poorest nations of the world, per capita expenditure on health care was cut by nearly 50 per cent (18). The overall quality of health services deteriorated. Although this trend might seem contrary to the previous observation that increased spending does not lead to improved health (9) there appears to be a minimal essential level of health expenditure (akin to a critical mass) below which health services are likely to suffer and above which increased expenditure is not likely to make a significant impact on health care outcome variables. Unfortunately, the exact cutoff point has not been determined. In addition, the devastating and rapidly spreading acquired immunodeficiency syndrome (AIDS) pandemic entered the scene and in those countries with high prevalence (mostly developing countries) a large share of drugs and hospital facilities were being diverted to the care of AIDS patients. In some instances, money for health is simply not there. It is being diverted and spent on the purchase of consumer goods, repair of roads and acquisition of military hardware (9). The Bamako initiative was promulgated in an attempt to devise community financing of health care by establishing local revolving funds accrued on revenue from the sale of drugs (19). In other words, the users of health services were called upon to pay for what they received through a fee-for-service scheme (20). The net result of this is that the drugs imported with the taxpayers' money are available only to a select few: those who can afford them (21). Now, with the end of the Cold War, greater world attention is being focused on the former Soviet Union (Eurasia) (22), while Africa and the rest of the developing countries are becoming increasingly marginalized. 


\section{Structural adjustment}

The austerity packages spelled out by the World Bank and the International Monetary Fund, under the banner of Structural Adjustment, called for the curtailment of government expenditure (abolition of government subsidies for basic foods, medicines and school books, as well as retrenchment of civil servants), currency devaluation and re-orientation of the economy towards the generation of foreign exchange through reduction of imports and export promotion. These measures, though theoretically attractive, in practice appear to have achieved the very opposite of what they were intended to do, at least in the short term. The measures concentrated on economic health, at the expense of social health. The lack of foreign exchange meant drugs and medical supplies could not be imported. The forced devaluation of local currencies resulted in the soaring of the cost of imported drugs and supplies, thus fuelling the crisis even further.

In developing countries medicine cannot be practised in the consulting room or operating theatre alone, but must be related to the social and community aspects of health and disease. When planning health care in developing countries priorities must first be given to those aspects of health and developmental programmes aimed at educating the population and raising the general standards of living. A sound medical programme cannot be established solely on the basis of economic progress, as Structural Adjustment would lead us to believe, but must be based on progress in other areas, such as education. Governments in developing countries have had to make agonizing decisions in trying to assign priorities to the long list of developmental needs.

Government is the largest single employer in most of the developing countries. When you lay off civil servants in Europe or North America, there is usually a strong industrial base to absorb them. When you lay off people in Canada or Sweden, there is an excellent social welfare service to take care of those retrenched. When you lay off a worker in any developed country, only one person (or at most the nuclear family) is affected. Not so in developing countries; there is no industrial base to speak of, social welfare schemes do not exist and the

\section{Table 2 Basic principles of medical ethics}

Preserve life

Alleviate suffering

Do no harm

Tell the truth

Respect the patient's autonomy

Deal justly with patients apparently single person who is retrenched, more often than not, supports an entire extended family and/or village. Thus Structural Adjustment, though excellent in theory, in practice takes no cognizance on of the realities of life in developing countries.

\section{Cost, scarcity and sacrifice}

To an economist, cost means sacrifice. When economists ask: 'What will it cost?' they are referring to more than the dollar value. The economist is indirectly asking: 'What will have to be sacrificed?' (23). The high cost of advanced technology has brought to reality the economist's classic problem of scarcity. Nowhere else in the world is the true meaning of scarcity portrayed as vividly as in the developing countries. There, the per capita expenditure devoted to health is less than US $\$ 5$ and in some countries it is less than US\$1. This is in 은 sharp contrast to the industrialized countries, where the average is US $\$ 1,000$ and in some countries, like $\mathcal{W}$ the USA, over US $\$ 2,000$ is spent on health care per capita (24). The lack of foreign exchange, due to the decline in world prices for primary commodities and the devaluation of currencies, meant that some things had to be sacrificed. Unfortunately, sociad services (health and education) were the first to suffer. Rigorous management of scarce health care. resources is necessary and unavoidable (25 Although rationing is a word which is not politically expedient, health care professionals, the health care industry, the public and political leaders must be prepared to acknowledge its need and not shirk the necessity (26). In addition, the public must voice its opinions and concerns on what needs to be rationed and whose entitlement should be curtailed.

\section{Doctors' dilemma}

The Stanford University Medical Center Committee on Ethics promulgated six basic principles on $\delta$ medical ethics (Table 2) (27). These principles are $₹$ often in conflict, yet resolving such conflicts is 을 central to the art of medicine. How, for instance, do $>$ you preserve life and alleviate suffering in the face of hunger, poverty and war? How do you tell the truth and respect the autonomy of your patient when the $\mathrm{N}$ relatives insist that the patient should not be told of $N$ the diagnosis? This conflict between patient and $\underset{\mathrm{N}}{\mathrm{N}}$ family can make it difficult for the physician to 0 discuss openly the disease process and its manage-

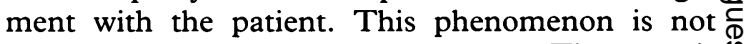
peculiar to developing countries alone. The same is $\stackrel{\mathbb{P}}{+}$ often observed in the culture of Southern $\square$ Europeans, especially those of Italian and Greek ethnic background. How do you remain ethical $\stackrel{D}{?}$ when the rest of the world around you appears to be $\mathbb{\otimes}$ unethical? Dealing justly with patients involves an $\overline{0}$ appeal to some underlying theory of distributive justice and the practice of egalitarian principles. In 
applying just dealing to communities such as Third World countries, doctors' clinical freedom often clashes with that of the authority allocating scarce resource on behalf of the community. Unfortunately, clinical freedom has the weaker claim and must be sacrificed. The liberal theory of justice calls for rules that govern international relationships (28). Such rules would provide an opportunity for the affluent nations to understand, and perhaps experience first-hand, the lifestyle of the underprivileged majority residing in the Third World.

Conflict further emerges for the doctor acting as the patient's advocate and, at the same time, serving as an agent for societal good. This conflict grows as the rationing of health care services increases. The concept of an essential drug list for many clinical conditions and the development of practice guidelines are becoming globally accepted. Such practice guidelines are intended to assist physicians in the diagnoses and treatments of specific disease conditions. The guidelines have been shown to be appropriate, effective and necessary for patient care. They are at the core of quality assurance programmes and should apply reliable methods that integrate research and clinical expertise. Finally, practice guidelines should be comprehensive and as specific as possible and should be based on up-todate information. While these practices might be seen as curtailing the doctor's clinical freedom, they are the surest way to deal with shortages in the face of shrinking financial resources. Whether doctors like it or not, there is no such thing as a value-free medicine. They must balance their technical success with a new sensitivity, a new humility and a new training.

\section{Triage and the greater good}

Triage is the sorting out of groups of sick and wounded persons and their classification, according to a system of priorities, in circumstances of mass casualties in the face of limited resources. Triage was originally a military concept in which the treatment of a slightly wounded soldier, who would then resume fighting, would take precedence over attending to a person with a life-threatening injury who would probably not regain combat fitness. Thus the policy of 'patient-centred ethics' is fundamentally antagonistic to the military goals. A military doctor is a soldier first and a doctor second.

The triage concept is very pertinent in an environment of limited resources, as in the Third World. It does not make sense to spend limited resources on those who will not benefit. Should patients with AIDS, for instance, in developing countries be treated with Zidovudine (AZT) or other similar drugs? Should individuals with incurable malignancies consume resources that could be applied to immunize children? The benefit alluded to above (outcome measure) has so far been based on traditional epidemiological measures of disease outcome, namely survival, disease-free interval and cure rates (29). These measures, unfortunately, are based on physician viewpoint (third party) and have tended to neglect the patient's subjective experience. In situations of limited resources, as is the case in most Third World countries, where 80 per cent of cases present with very advanced incurable malignancies, the primacy of palliation cannot be over-emphasized (30). The goal of palliation is the attainment of the highest quality of life for patients and their families. In this situation the physician should not consider survival benefit only but should ensure a comfortable terminal illness, death without pain and death with dignity, as equally meritorious.

Data from the Cardiff Health survey presented by Lewis and Charny (31), suggest that society would be prepared to apply the triage principle and choose, on the basis of age between two individuals requiring treatment, in a situation where resources allowed the treatment of only one. This concept, also referred to as the 'greatest good for the greatest number', assumes and advocates a utilitarian health policy. If such a policy were to be embraced, a significant proportion of individuals would suffer. Societal decisions in these matters are guided by the utilitarian worth, the worth of a human being, and investment by society, as well as by the notions of justice and compassion. While the concept of greater good would seem theoretically appealing, in reality, society continues to care for the severely handicapped, recidivists and those chronically ill at considerable expense. Thus society does not view the greater good in purely utilitarian terms, but in terms of a complex mixture of competing philosophies (32). While society demands the wise spending of its resources, it is also painfully aware of its responsibilities to all its members and that these responsibilities can only be met through the expenditure of resources.

While I concede that health priorities in developing countries centre around the control of infectious diseases, malaria, the provision of clean water and the prevention of diseases like cancer and heart disease, this greater good must not be permitted to prevail over concerns and responsibilities in other areas. In other words, we cannot push prevention at the expense of those who are currently sick. Even if we were to eliminate the hepatitis $\mathbf{B}$ virus through global vaccination or persuade all people to stop smoking today, we will still have to contend with people dying of liver cancer and tobacco-related diseases for the next ten to thirty years. Our responsibilities to these people will remain. Any intervention for the good of the community must still be weighed against a possible loss of personal autonomy. It should, in any case, be remembered that most murderous and totalitarian regimes have acted in the so called interest of the greater public good. 


\section{Conclusion}

Health care reforms in developing countries must not merely copy what is being done in the industrialized countries. They should be directed towards fostering self-help schemes so that the fruits of intervention can be multiplied and development becomes self-sustaining. The issues that need to be addressed include inter alia: how to get away from an almost 100 per cent government funding of health care; how to take health care services to the rural areas where the population resides; how to involve the populace in their own health promotion, and how to ensure that ethics is brought back into health care practice and into the society itself.

So many private clinics mushroomed during the difficult economic era - how can these be controlled, so as to protect the consumer? Should health ministries in developing countries continue to defray the exorbitant costs of overseas treatment for a select privileged few while the majority cannot get aspirin for pain relief or hospital bed linen or clean water? Should medical education in developing countries include resource management in its curriculum? Finding the answers to these questions will be difficult but these sorts of questions would provide the basic framework for health care reform in developing countries.

Charles Olweny, MD, is Professor of Medicine at the University of Manitoba and Co-Director of the World Health Organisation Collaborating Centre for Quality of Life in Cancer Care, St Boniface General Hospital, Winnipeg, Manitoba, Canada.

\section{References}

(1) Mathews T, Meyer M, Foote D, et al. The siege of LA. Newsweek 1992 May 11: 30-38.

(2) Hare N, Hare J. Crossover justice. In: Madhubuti $\mathbf{H}$ $\mathrm{R}$, ed. Why LA happened: implications of the '92 Los Angeles rebellion. Chicago: Third World Press, 1992: 74-81.

(3) Clements C. Doctors' dilemma: lawyers and insurers are crowding out physicians. The Medical Post 1993 Feb 16: 44

(4) Benjamin W W. Combining the best of two medical worlds: Canadian universality and United States freedom. Humane medicine 1992; 8: 271-285.

(5) Quality health for Manitobans: the action plan. Manitoba health 1992 May.

(6) Clinton B. The Clinton health plan. New England journal of medicine 1992; 327: 804-807.

(7) Wellstone P D, Shaffer E R. The American Health Security Act: a single payer proposal. New England journal of medicine 1993; 328: 1489-1493.

(8) Alma Ata declaration: health for all by the year 2000? International Conference on Primary Health Care. WHO \& UNICEF, Alma Ata, USSR: 1978 Sept 6-11.
(9) Olweny C L M. Global inequalities in cancer care. Transactions of the Royal Society of Tropical Medicine and Hygiene 1991; 85: 709-710.

(10) Schieber G J, Poullier J P, Greenwald L M. US $\vec{F}$ health expenditure performance: an international comparison and data update. Health care finance review 1992; 13, 4: 1-15.

(11) Relman A S. The health care industry: where is it $\frac{\bar{S}}{\partial}$ taking us? New England journal of medicine 1991; 325: 854-859.

(12) Berger J. Forced health care rationing is never ethical. The Medical Post 1992 Nov 24: 22.

(13) Miles S H, Lurie N, Quam L, Caplan A. Health care reform in Minnesota. New England journal of medicine 1992; 327: 1092-1094.

(14) Sager A. Prices of equitable access: the new Massachusetts health insurance law. Hastings Center i report 1988; 18, 3: 21-25.

(15) Steinbrook R, Lo B. The Oregon Medicaid demonstration project - will it provide adequate $\overparen{\sigma}$ medical care? New England journal of medicine 1992; 326: 340-344.

(16) Hughes J. How well has Canada contained the costs of doctoring? Fournal of the American Medical Association 1991; 265: 2347-2351.

(17) Berer M L, Evans R G. Interpreting Canada: models, mindsets and myths. Health affairs 1992; 11: 44-61.

(18) Summerfield D. Western economics and Third World health. Lancet 1989; 2: 551-552.

(19) UNICEF. Report: The state of the world's childre 1988.

(20) Anonymous [editorial]. Structural adjustment a health in Africa. Lancet 1990; 335: 885-886.

(21) Ityavyar D A. Health services inequalities in Nigeria Social science and medicine 1988; 27: 1223-1225.

(22) Gettert G A. International health assistance for $\mathbb{D}$ Eurasia. New England journal of medicine 1992; 326: 1021-1026.

(23) Williams A J. Cost-effectiveness analysis: is it ethical? fournal of medical ethics 1992; 18: 7-11.

(24) Olweny C L M. Health in Africa: a call for attainable targets. Manitoba medicine 1992; 62:18-20.

(25) Maynard A. Occasional book: healthy competition. Lancet 1990; 336: 1305.

(26) Veatch R M. Allocating health resources ethically: new roles for administrators and clinicians. Front health administration 1991; 8: 3-29.

(27) Ruark J E, Raffin T A. The Stanford University $O$ Medical Center Committee on Ethics: initiating and withdrawing life support. New England journal of medicine 1989; 15: 25-30.

(28) Barry B. The liberal theory of justice. Oxford: N Clarendon Press, 1973.

(29) Olweny C L M. Quality of life in cancer care. Medical journal of Australia 1993; 158: 429-432.

(30) Olweny C L M. Quality of life in developing countries. Fournal of palliative care 1992; 8, 3: 25-30.0

(31) Lewis R A, Charny M. Which of two individuals do $\frac{\Gamma}{\Phi}$ you treat when only the ages are different and you can't treat both? fournal of medical ethics $1989 ; 15$ : 7 28-32.

(32) Whitaker P. Resource allocation: a plea for a touch of $\frac{}{\mathbb{D}}$ realism. Fournal of medical ethics 1990; 16: 129-131. 